\title{
A PRÁTICA PEDAGÓGICA MEDIADA POR TECNOLOGIAS E APLICATIVO DIGITAL NA EDUCAÇÃO INFANTIL
}

\author{
Ana Paula Rodrigues Machado - UFSM - anapaularm130@gmail.com, \\ https://orcid.org/0000-0002-7419-1060 \\ Ana Cláudia Oliveira Pavão - UFSM - anaclaudiaoliveirapavao@ gmail.com, \\ http://orcid.org/0000-0002-9914-3700
}

Resumo: Este trabalho tem por objetivo avaliar o uso de dispositivos móveis na Educação Infantil, por meio de um aplicativo Digital Storytelling, considerando o brincar das crianças e suas diferentes linguagens. Para tal, a metodologia envolveu pesquisa aplicada, com abordagem qualitativa, do tipo exploratório-explicativa. Quanto aos procedimentos, parte de um delineamento de pesquisa netnográfica. O lócus da pesquisa é uma Escola Pública, localizada no interior do Rio Grande do Sul, tendo como sujeitos, quatro professores. O instrumento utilizado foi uma entrevista on-line. A análise dos dados partiu de duas categorias, Mediação de tecnologias digitais e potencial pedagógico para desenvolvimento infantil. Os resultados apontam para a ressignificação do fazer pedagógico durante o ensino remoto, abrindo espaço para a inserção de tecnologias digitais no retorno presencial. Pode-se concluir que, as práticas pedagógicas mediadas pelo aplicativo digital Toontastic $3 D$ proporcionaram às crianças o brincar, com narrativas lúdicas, desenvolvidas a partir de diferentes linguagens, potencializando os processos de desenvolvimento infantil.

Palavras-chave: Educação Infantil. Dispositivos Móveis. Narrativas Digitais. Aplicativo Digital Storytelling Toontastic 3D.

\section{THE PEDAGOGICAL PRACTICE MEDIATED BY TECHNOLOGIES AND DIGITAL APPS IN A PRESCHOOL}

Abstract: This study paper aims to evaluate the use of mobile devices in a Preschool, through a Digital Storytelling app, considering the playing of children and their different languages. The method involved applied research, with a qualitative approach, of an exploratory-explanatory type. As for the procedures, it is part of a netnographic research design. The locus of the research is a Public School, located in the interior of Rio Grande do Sul, having as subjects, four teachers. The instrument used was an on-line interview. Data analysis started from two categories, Mediation of digital technologies and pedagogical potential for child development. The results point to the resignification of pedagogical practice during remote teaching, opening space for the insertion of digital technologies in the face-to-face return. It can be concluded that the pedagogical practices mediated by the Toontastic 3D digital app provided children with playing, with play full narratives, developed from different languages, enhancing the child development processes.

Keywords: Preschool. Mobile devices. Digital Narratives. Digital Storytelling Toontastic 3D apps.

\section{INTRODUÇÃO}

A educação, na atualidade, passa por muitos desafios, entre eles, propor práticas pedagógicas voltadas ao uso das Tecnologias da Informação e Comunicação - TIC, beneficiando alunos e professores nos processos de ensino-aprendizagem. Na Educação 
Infantil, esse processo envolve o brincar no desenvolvimento e aprendizagem das crianças. Gomes (2016, p. 153), esclarece que as TIC são "uma ferramenta de aprendizagem que faz uso da brincadeira", proporciona uma pedagogia lúdica, direcionada e midiatizada. Para Borba (2006, p. 39), “[...] a brincadeira é um fenômeno da cultura, uma vez que, configura-se como um conjunto de práticas, conhecimentos e artefatos construídos e acumulados pelos sujeitos nos contextos históricos e sociais em que eles se inserem". Gomes (2016) ressalta a importância do brincar não só na primeira infância, mas sim, em toda a trajetória de vida dos sujeitos.

Considerando o contexto da globalização, o brincar acompanhou as transformações em diferentes épocas. Antes, os brinquedos eram de madeira e artesanais, após esse momento, passaram a ser de plástico e, em diferentes cores e formas. Os brinquedos estáticos seguiram as inovações tecnológicas e ganharam vida, com sons, luzes e movimentos. E assim, o novo artefato eletrônico, como: console, vídeos games, tablets e smartphones encantam pelas suas diferentes possibilidades de brincar, criar e se divertir. E, neste compasso, as novas gerações digitais dominam seu espaço, e a tecnologia passou a ser cotidiana, fazendo o brincar, cada vez mais tecnológico. Segundo Friedman (2009, p. 26), "cada geração de crianças transforma brincadeiras antigas, ao mesmo tempo em que cria as suas próprias, especificas", mudando a forma do brincar, ajustando a diferentes épocas, não deixando de ser criança.

Nesse contexto, é necessário pensar em recursos tecnológicos de fácil acesso e manuseio, e que sejam do cotidiano das crianças, como: celulares, smartphones, tablets, softwares e aplicativos digitais infantis que, inseridos de forma adequada podem influenciar, significativamente, o processo de formação da criança. Gomes (2012) corrobora sobre aspectos relevantes que podem beneficiar no processo de desenvolvimento e aprendizagem, a partir do uso das TIC, como: coordenação motora, pensamento lógico/matemático, a linguagem, o conhecimento do mundo e diversidade.

Dentre as possibilidades de inserir as TIC na educação infantil, destaca-se o uso de dispositivos móveis e aplicativos digitais ou book-app, como o Toontástic 3D, do Google. Este aplicativo difere-se por proporcionar ao usuário uma experiência imersiva e interativa de Storytelling que, em português, tem o significado de narrativa (Miller, 2014), estimulando a tomada de decisão, conhecimento e o protagonismo infantil. Esta experiência imersiva ao Storytelling refere-se ao uso de novas tecnologias, como a Realidade Aumentada (AR), Realidade Mista (MR), Realidade Virtual (VR) e material visual em $360^{\circ}$ elaborado para a criação de plataformas consideradas interativas.

O aplicativo Digital Storytelling Toontastic 3D possibilita a criação de narrativas inéditas, através de recursos multimídia, proporcionando interatividade entre o usuário e o aplicativo, em uma experiência imersiva, do sujeito que cria a narrativa, ao sujeito que experiencia a narrativa, no formato de desenho animado em vídeo $\mathrm{mp} 4$. O aplicativo pode ser utilizado por crianças a partir de três anos, pois apresenta layout de fácil acesso, com imagens que direcionam o usuário à criação de histórias digitais a partir da sua própria voz, por meio da ferramenta de gravação de áudio.

Tendo em vista o exposto, esse trabalho tem por objetivo avaliar o uso do aplicativo Digital Storytelling Toontastic $3 D$ como prática pedagógica na Educação Infantil, considerando o brincar das crianças e suas diferentes linguagens.

\section{MÉTODO}

Essa pesquisa é de natureza aplicada e apresenta abordagem qualitativa, com objetivo exploratório - explicativo (GIL, 2017). Quanto aos procedimentos, esse estudo caracteriza-se como uma pesquisa netnográfica. De acordo com Kozinets (2014, p. 61/62), a netnografia é uma "pesquisa observacional participante, baseada em trabalho de 
campo on-line" e utiliza-se de comunicações mediadas pelas TIC como fonte de dados para alcançar o entendimento das ideias ou conceitos de um determinado fenômeno cultural.

O lócus da pesquisa é uma escola de Educação Infantil, no interior do Rio Grande do Sul, e teve como participantes quatro professores, denominados nesse estudo como: $\mathrm{P} 1, \mathrm{P} 2, \mathrm{P} 3$ e $\mathrm{P} 4$.

Como instrumento de coleta de dados, utilizou-se a entrevista on-line, pelo Google formulário. A análise dos dados obtidos pelas entrevistas on-line foi realizada por meio da interpretação das falas dos professores envolvidos na pesquisa e organizada em categorias, de acordo com Bardin (2011), que são: Mediação de tecnologias digitais e potencial pedagógico para desenvolvimento infantil. A Mediação de tecnologias digitais envolve o uso do aplicativo digital nas práticas pedagógicas durante o ensino remoto emergencial como estratégia para manter os vínculos entre as crianças e a escola; e o Potencial pedagógico para desenvolvimento infantil, definido a partir da utilização de tecnologia digital, para e com as crianças, por meio de narrativas lúdicas e divertidas.

\section{RESULTADOS E DISCUSSÕES}

\section{Lócus e sujeitos da pesquisa}

A definição pela escola de Educação Infantil foi essencial para o desenvolvimento da pesquisa, pois se utiliza da concepção da criança em sua centralidade, primando pelos processos interacionais com ênfase no brincar da criança.

A proposta pedagógica da escola embasa-se nas orientações das Diretrizes Curriculares Nacionais para a Educação Infantil- DCNEI (2010), e tem como eixos norteadores, as interações e as brincadeiras, promovendo experiências significativas que lhes possibilitem viver plenamente sua infância. Atualmente, em decorrência da pandemia causada pela Covid-19, as práticas pedagógicas que antes eram realizadas presencialmente, agora, devido ao isolamento físico, estão sendo realizadas por meio do ensino remoto, ou seja, de forma on-line, utilizando-se de ambientes virtuais de aprendizagem, redes sociais e aplicativos de videoconferência.

Os participantes desse estudo são quatro professores, com graduação em Pedagogia e Pós-graduação em Educação. Dos quatro professores, três relatam ter experiência em TIC, por meio de cursos e experiência no ensino EAD e, apenas um professor relata não ter experiência em TIC na educação.

\section{Implementação do Aplicativo Digital Storytelling Toontastic 3D}

O aplicativo Toontastic $3 D$ foi implementado pelos professores em suas práticas pedagógicas, considerando o ensino remoto. As práticas pedagógicas de cada professor respeitaram o brincar da criança e suas diferentes linguagens, com histórias lúdicas e divertidas, charadas e narrativas com a temática "quem sou eu". Desse modo, a estratégia para manutenção dos vínculos entre crianças e professoras ocorreu com a utilização do aplicativo e suas potencialidades por meio do desenvolvimento de narrativas únicas, aliadas a voz das próprias professoras, aproximando a todos. Para além das narrativas, as interações das crianças ocorreram de forma on-line, por mensagens em rede social. A cada nova história, as crianças eram instigadas a ouvir e responder as charadas. Estas narrativas trouxeram personagens lúdicos, apresentando características de cada criança, permitindo assim, conhecer-se a si mesma e as outras crianças. As narrativas fizeram uso de diferentes linguagens, como poemas, histórias e charadas, aliadas a desenhos e imagens em 3D. 


\section{Categoria Mediação de tecnologias digitais nas práticas pedagógicas}

$\mathrm{Na}$ organização das práticas pedagógicas é fundamental a escuta das crianças e, nesse processo de escuta é que se conhece suas histórias de vida, interesses, singularidades e seus contextos e, a partir desse conhecimento, oferta-se experiências significativas que possam enriquecer seu repertório de aprendizagens. Esse processo de escuta não se limita apenas à fala, mas, aos gestos, olhares, em suas diferentes expressões, sentimentos com todos os nossos sentidos (RINALDI, 2012).

Em relação às práticas pedagógicas, as professoras desenvolveram diferentes narrativas, como convites para encontros on-line e informações às famílias de modo lúdico e divertido. A participante $\mathrm{P} 1$ produziu um convite para encontro on-line da turma, e disponibilizou um vídeo de uma experiência com feijões, no qual narra o passo a passo desde o plantio até o nascimento dos feijões. As participantes P2 e P4 desenvolveram 24 narrativas de charadas "o que é o que é?", 17 narrativas de "quem sou eu?", as quais narram as características de cada criança, trazendo seus brinquedos e brincadeiras preferidos, dois convites para encontro on-line, um poema de dia das crianças e um cartaz. A participante P3 criou quatro narrativas durante a pesquisa, entre elas: "querem qual história?" na qual a professora instiga aos alunos a interagir com as histórias sobre aventuras no fundo do mar e piratas, além de um convite para uma visita on-line ao museu. A figura 1 ilustra duas narrativas digitais desenvolvidas pelo aplicativo Toontastic $3 D$ por P1 e P4.

Figura 1- Convite on-line e Charada "O que é o que é?"

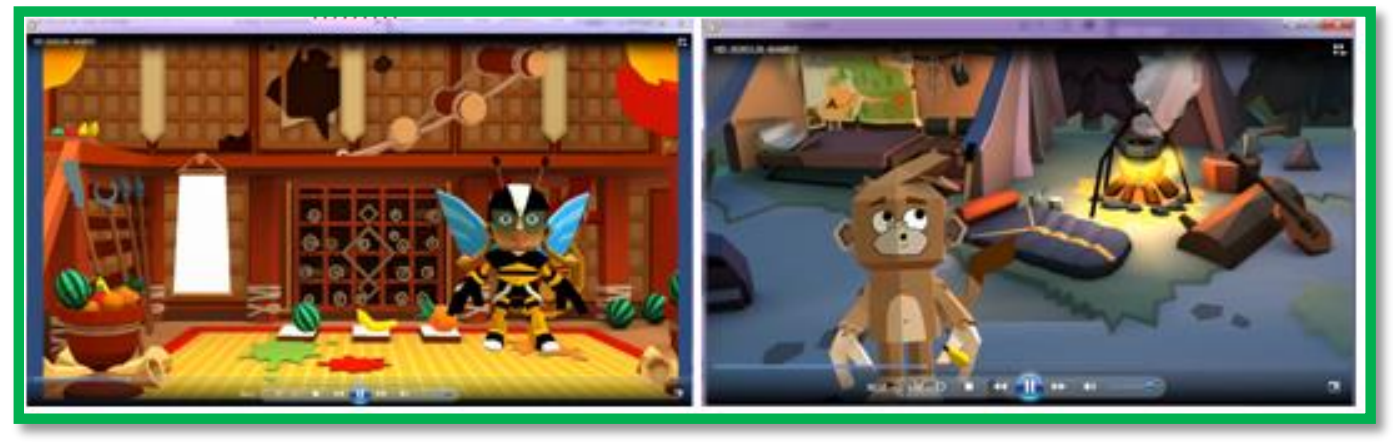

Fonte: Dos autores.

Considerando o atual momento pandêmico em que estamos vivenciando, ofertar às crianças oportunidades de experienciar tecnologias digitais interativas e lúdicas, que permitiram o brincar, mesmo estando longe da escola, possibilitou a elas receberem um pouco da escola em seu cotidiano familiar. A interatividade das narrativas desenvolvidas beneficia de modo significativo o processo de desenvolvimento da criança na primeira infância, oportunizando a ela vivências e aprendizagens divertidas e lúdicas com o uso de tecnologia digital. De acordo com Cecchin e Reis (2014), as narrativas têm a capacidade de ampliar os processos de aprendizagem, o conhecimento e a criatividade, a partir das experiências vivenciadas. Ferreira e Filho (2020) corroboram sobre aspectos relevantes na criação e desenvolvimento de narrativas, como prática pedagógica, que agrega a ludicidade e motivação, por meio do brincar e aprender, engajando as crianças em sua própria aprendizagem. 
Percebeu-se durante a pesquisa, os benefícios que a prática pedagógica mediada por tecnologia digital oportunizou aos participantes e às crianças. Aos professores, o conhecimento e a experiência da prática ao utilizar um aplicativo ainda nunca experienciado por eles e, às crianças, a surpresa a cada dia que recebiam as histórias por rede social. Esta experiência pode ser verificada através das falas dos participantes sobre a utilização do aplicativo Digital Storytelling Toontastic $3 D$ e o desenvolvimento de narrativas digitais:

\begin{abstract}
Foi uma experiência positiva, o aplicativo possui vários recursos e possibilidades na criação de histórias e com diferentes objetivos, como por exemplo, comunicar informações, fazer um convite, contar sobre experiências científicas e criar brincadeiras com os diferentes personagens e cenários. As trilhas sonoras disponíveis e de fácil acesso ajudam a criar a ambientação da cena, e pré-organização dos créditos facilita muito na organização dos vídeos (P1).
\end{abstract}

Considerando a fala de P1, Psomos e Kordaki (2012) discorrem sobre as qualidades que o Aplicativo Digital Toontastic $3 D$ oferece, em relação à criatividade e inovação, as representações múltiplas e a motivação para criar e narrar histórias inéditas e surpreendentes, utilizando-se de recursos multimídia em um ambiente imersivo e interativo.

Foi uma experiência bem desafiadora, uma vez que ainda não havia tido contato com o app, mas, proporcionou nos desafiarmos a pensar que possibilidades eles poderiam auxiliar, então criamos histórias, brincadeiras de charadas e adivinhações $(\mathrm{P} 2)$.

Como buscamos diferentes estratégias para chamar o interesse das crianças o Toontastic 3D, foi mais uma possibilidade lúdica para abordarmos diferentes temáticas, desafiar as crianças e instigá-las com personagens que se aproximam do universo infantil e, ao mesmo tempo, dos professores e bolsistas. Pois podemos colocar nossa imagem e áudios com as nossas falas (P4).

Nicolopoulou (2011) destaca a ênfase nas narrativas criadas no aplicativo Digital Storytelling Toontastic 3D, a partir de seus recursos multimídia, pela experiementação, reflexão e interação promovendo aprendizagens significativas. Nicolopoulou (2011) e Ong (2011) complementam que o aplicativo proporciona o brincar e aprender de forma significativa, tornando-se aliado nas práticas escolares com crianças. A utilização do aplicativo durante o ensino remoto possibiltou a manuntenção dos vínculos com as crianças e das crianças com os professores e a interação e participação no contexto familiar.

Com relação às práticas pedagógicas mediadas por tecnologia digital e a criação de narrativas pelo aplicativo Digital Storytelling Toontastic $3 D$ durante o ensino remoto, as professoras participantes relatam que a experiência foi significativa, levando em consideração o contexto da pandemia. As práticas pedagógicas mediadas pelas TIC durante o ensino remoto trazem reflexões em torno da Educação Infantil e o fazer pedagógico mediado pelas tecnologias digitais.

Eu acredito que as narrativas da forma como foi incluída no contexto da turma, foi enriquecedora. Aproximando as crianças das professoras de modo que algumas aguardavam pelos desafios (P2). 
O Conselho Nacional de Educação (CNE) publicou, em abril, o Parecer $n^{\circ}$ 05/2020 com recomendações quanto à reorganização das atividades escolares não presenciais, considerando a Educação Infantil e a importância da ação educativa, aproximação e fortalecimento de vínculos com as famílias e as crianças e interação social, salientando a necessidade de propor atividades on-line como jogos, brincadeiras, conversas e histórias com a intencionalidade e objetivos de estimular novas aprendizagens (BRASIL, 2020a). Desta forma, professores e educadores precisam adaptar-se nesse momento, para atender a demanda das crianças, respeitando suas necessidades e fases do seu desenvolvimento. Na fala de P3 e P4,

Muito válida, pois os meios digitais tornaram-se nossa principal ferramenta de trabalho, no ensino remoto $(\mathrm{P} 3)$.

As narrativas nos aproximaram do universo das crianças e possibilitaram muitas brincadeiras lúdicas e aprendizagens. Criamos situações que desafiaram as crianças, que as aproximaram umas das outras nesse momento de pandemia (P4).

O emprego de tecnologias digitais que proporcionem às crianças interação e brincadeira é essencial ao seu desenvolvimento, aprendizagem e protagonismo infantil. A Lei ${ }^{\circ} 14.040 / 2020$ que estabelece normas educacionais excepcionais a serem adotadas durante o estado de calamidade pública, as Secretarias de Educação e as instituições escolares, devem elaborar orientações/sugestões aos pais ou responsáveis sobre atividades que possam ser realizadas com as crianças em seus lares, durante o período de isolamento imposto pela pandemia, entre eles "[...] brincadeiras, jogos, músicas infantis e até algumas atividades em meios digitais quando for possível, transformando os momentos cotidianos em espaços de interação e aprendizagem" [...] (BRASIL, 2020b, p. 10). O documento esclarece e orienta quanto ao desenvolvimento de atividades pedagógicas não presenciais na Educação Infantil, considerando os objetivos de aprendizagem e desenvolvimento e os campos de experiência propostos pela BNCC, e orientações pertinentes quanto ao uso das TIC, promovendo atividades de estímulo cognitivo, socioemocional e experiências lúdicas com espaço para brincadeiras (BRASIL, 2020b).

Pode-se perceber nos relatos, que o aplicativo Digital Storytelling Toontastic 3D possibilitou o brincar em suas diferentes formas, a partir das narrativas desenvolvidas pelos professores. Corsino (2012, p. 06) ressalta que, "a brincadeira fornece ampla estrutura para mudanças das necessidades e da consciência, pois nela as crianças ressignificam o que vivem e sentem". Nas propostas e brincadeiras com as crianças, a linguagem norteia as interações vivenciadas em suas diferentes fases de desenvolvimento. Considerando o brincar através do aplicativo Digital Storytelling Toontastic $3 D$, as crianças têm a possibilidade de se divertir e aprender ampliando seu repertório comunicativo em interação com tecnologias digitais, o que beneficia seu desenvolvimento.

\section{Categoria Potencial Pedagógico para o Desenvolvimento Infantil}

Em relação ao potencial pedagógico para desenvolvimento infantil a partir da utilização de tecnologias digitais, as práticas pedagógicas mediadas pelas TIC, corroboram não somente como potencializador dos processos de aprendizagem, como favorecem a inclusão tecnológica, permitindo o acesso a recursos e serviços de tecnologia desde a infância. Nos relatos de P1, P2 e P3: 


\begin{abstract}
As tecnologias digitais podem ser nossas aliadas como recurso que dão apoio em propostas diversas, ampliando o repertório de brincadeiras e explorações das crianças. Por exemplo, agora durante a pandemia tem surgido oportunidades ímpares de visitas a museus que seria muito difícil visitar, considerando a distância (Pl).
\end{abstract}

É importante incluir o mundo digital que já faz parte dessa infância. Que, muitas vezes, ele vem dominando muito bem, talvez esse seja um ponto importante a repensar ( $P 2)$.

O aprendizado, a criação, exploração e o imaginário das crianças (P3).

A partir dos relatos dos participantes em relação ao uso de dispositivos móveis e tecnologia digital em suas práticas pedagógicas na Educação Infantil, reforça-se o que dizem Coll e Martí (2001) e Coll e Monereo (2010) sobre as potencialidades que o uso de tecnologia representa para os processos de desenvolvimento da criança. Ao pensar em propostas para a Educação Infantil utilizando-se de tecnologia, o educador deve pensar em um ensino personalizado (ARETIO, 2012), considerando as especificidades de cada um, o tempo disponível, o tipo de proposta e os objetivos que se espera alcançar.

Esse app é bem interessante, abre espaço para o desenvolvimento das linguagens, bem como potencializa o uso do celular para outros vieses. Não havia tido contato com o app até o momento da pesquisa, o que possibilitou observar seus recursos, de acordo com o retorno das crianças, uma dica seria poder inserir características no seu personagem, além da possibilidade do desenho $(P 2)$.

As práticas pedagógicas na Educação Infantil diferem-se por priorizar as interações e brincadeiras como essenciais para o desenvolvimento infantil. O potencial pedagógico do aplicativo Digital Storytelling Toontastic $3 D$ em propostas para as crianças ressignificou o fazer pedagógico durante o ensino remoto, abrindo espaço para a reflexão em torno das práticas mediadas pelas TIC. Estas práticas corroboram não somente como potencializador dos processos de aprendizagem, com a utilização de aplicativos digitais que mediam este processo, como também favorecem a inclusão tecnológica, permitindo o acesso a recursos e serviços de tecnologia desde a infância.

A partir dos relatos dos professores, o aplicativo Digital Storytelling Toontastic $3 D$ foi decisivo para a manutenção de práticas pedagógicas inovadoras considerando o contexto do ensino remoto e as especificidades desta modalidade de ensino para a educação infantil. Assim, quando do retorno ao ensino presencial, os participantes da pesquisa relatam as possibilidades que poderão ser desenvolvidas com uso do aplicativo em suas propostas de forma interativa e colaborativa.

Sim! Acredito que presencialmente ele poderia ser mais explorado, visto que, teria acompanhamento do professor que poderia propor a associação entre as experiências da vida real com a criação de histórias através da realidade virtual, propor espaços de apresentação e apreciação dessas criações, etc. (P1).

Moyles (2002, p. 27) relata a importância da mediação do educar a criança e a brincadeira, e ressalta que, "o brincar dirigido pela professora canaliza a exploração e a aprendizagem do brincar livre e leva as crianças a um estágio mais avançado de entendimento". Nos estudos de Kishimoto (2011) e Corsino (2012), o brincar faz parte da vida da criança e, neste brincar, ela aprende e nessa vivência, ela constrói sua aprendizagem. Czyzeswki e Werle (2017, p. 373) relatam a importância do brincar na 
infância como um "ato de construção do pensamento, recriação da realidade, construção de linguagens, portanto, constitui aprendizagens", e este brincar precisa ser divertido, com engajamento necessário e significativo às construções do conhecimento.

Como é um aplicativo pelo celular, acredito que na escola poderíamos colocálo no tablet e disponibilizar para as crianças, potencializando as oralidades, criatividades e criações de enredo (P2).

P2 relata que o aplicativo Digital Storytelling Toontastic $3 D$ em uma proposta de ensino presencial, poderá ser potencializador de novas aprendizagens, através da criação de narrativas criativas. Coll (2001), em seus estudos descreve o triângulo interativo, no qual a aprendizagem é o resultado de uma relação interativa entre professor, aluno e as propostas de ensino mediadas pelas TIC. Lalueza et al. (2010, p. 63) corroboram a partir dos estudos sobre Digital Storytelling que "as possibilidades abertas pelas TIC na construção de narradores serão, sem dúvida, um elemento fundamental nos estudos dos processos evolutivos do futuro". Pensar em propostas utilizando as narrativas digitais desde a Educação Infantil, priorizando o brincar de forma interativa e divertida, beneficia as crianças em seu processo de apropriação e construção do conhecimento, mediado pelas TIC, tecnologia digital e dispositivos móveis.

Podemos verificar na fala dos participantes que, mesmo distantes fisicamente e conectados virtualmente, o aplicativo Digital Storytelling Toontastic 3D demonstrou capaz de proporcionar às crianças, interação e brincadeira, considerando as Diretrizes Curriculares Nacional para Educação Infantil em propostas que priorizaram o brincar da criança em suas diferentes linguagens.

\section{CONCLUSÃO}

As narrativas fazem parte do cotidiano infantil, seja na escola ou no meio familiar, pela contação de histórias ou acontecimentos da vida. A oferta de diferentes narrativas em um contexto educacional, promove o brincar e, nesse brincar, as crianças criam e recriam as narrativas vivenciadas, apropriando-se de antigos e novos conceitos, relacionando com a vida e o mundo, produzindo cultura. Estas narrativas têm-se ressignificado com o uso de aplicativos digitais, que potencializam e inovam o ato de narrar histórias em vídeos animados e interativos.

As práticas pedagógicas que foram desenvolvidas a partir da utilização do aplicativo Digital Storytelling Toontastic 3D, possibilitaram aos participantes uma experiência imersiva ao Storytelling, contribuindo para a criação de narrativas digitais lúdicas e divertidas, com recursos interativos, como a ferramenta de desenho em 3D e a câmera instantânea, complementando a interatividade entre o usuário e o aplicativo digital.

Desse modo, busca-se responder ao objetivo que foi proposto inicialmente, de avaliar o uso de aplicativo Digital Storytelling Toontastic 3D como prática pedagógica na Educação Infantil, considerando o brincar das crianças e suas diferentes linguagens.

Em relação à primeira categoria, a mediação de tecnologias digitais, pode-se verificar a partir dos dados coletados, que o aplicativo Toontastic $3 D$ proporcionou a interatividade com o Storytelling, beneficiando de forma significativa as práticas pedagógicas desenvolvidas na Educação Infantil, durante o ensino remoto. A mediação ocorreu através de propostas lúdicas e divertidas, que instigaram as crianças à reflexão, ao pensamento lógico, à tomada de decisão, e ao conhecimento de si mesma, dos outros e do mundo que a cerca.

Quanto ao potencial pedagógico para o desenvolvimento infantil, pode-se inferir que as práticas pedagógicas mediadas pelo aplicativo proporcionaram interação e 
brincadeiras em contextos ricos e desafiadores, como histórias inéditas e charadas. Este contexto oportunizou às crianças a apropriação de novos conceitos, ideias, experiências e interatividade com a tecnologia digital.

A inclusão de tecnologias digitais na Educação Infantil por meio de propostas lúdicas e divertidas proporcionou a ressignificação do fazer pedagógico durante o ensino remoto, abrindo espaço para a inserção de tecnologias digitais no retorno do ensino presencial, promovendo um ambiente rico e desafiador, onde as interações e brincadeiras são essenciais à construção de sua identidade, favorecendo os processos de aprendizagem infantil.

Por fim, pode-se concluir que as práticas pedagógicas mediadas pelo aplicativo digital Toontastic $3 D$ durante o ensino remoto, proporcionaram às crianças o brincar, com narrativas lúdicas e divertidas, desenvolvidas a partir de diferentes linguagens, potencializando seus processos de desenvolvimento e aprendizagem.

\section{REFERÊNCIAS BIBLIOGRÁFICAS}

ARETIO, L. G. Sociedad Del Conocimiento Y Educación. Madrid: Editorial Aranzadi, 2012.

BARDIN, L. Análise de conteúdo. Trad. de Luís Antero Reto, Augusto Pinheiro. São Paulo: Edições 70, 2011.

BORBA, A. M. O brincar como modo de ser e estar no mundo. In: MEC/SEF. Ensino fundamental de 9 anos: orientações para a inclusão das crianças de seis anos de idade. Brasília, Ministério da Educação, 2006.

BRASIL. Ministério da Educação. Secretaria de Educação Básica. Diretrizes curriculares nacionais para a Educação Infantil / Secretaria de Educação Básica. Brasília: MEC, SEB, 2010.

BRASIL. Ministério da Educação. Conselho nacional de educação. Parecer $\mathbf{n}^{\mathbf{0}}$ 05/2020 orienta a Reorganização do Calendário Escolar e da possibilidade de cômputo de atividades não presenciais para fins de cumprimento da carga horária mínima anual, em razão da Pandemia da COVID-19. Brasília, 2020a. Disponível <http://portal.mec.gov.br/index.php?option=com_docman\&view=download\&ali as $=14511$-pcp005-20\&category_slud=marco-2020-pdf \&Itemid=30192>. Acesso em $11 / 12 / 2020$.

BRASIL. Ministério da Educação. Conselho nacional de educação. Lei no 14.040/2020, que estabelece normas educacionais excepcionais a ser adotado durante o estado de calamidade pública reconhecido pelo Decreto Legislativo n⿳0 6/2020. Brasília, 2020b. Disponível em:http://www.planalto.gov.br/ccivil_03/_ato20192022/2020/lei/L14040.htm. Acesso em 10/12/2020.

CECCHIN, A. de S.; REIS, S. C. dos. A Prática de Multiletramentos no Contex to Escolar Público: relatando experiências na produção de narrativas digitais em aulas de língua portuguesa. Renote. v. 12, n. 2, 2014. Disponível em: https://seer.ufrgs.br/renote/article/view/53514/33030. Acesso em 18 de março de 2021.

COLL, C. Constructivismo y education: lá concepción constructivista de a anseñanza y El aprendizaje. Em: COLL, C; PALACIOS, J. e MARCHESI,A.(comps). Desarrollo psicológico de La educación. V.2. Psicología de La Eduacion escolar: Madri: Alianza (p.p 157-186), 2001.

COLL, C.; MONOREO, C. Psicologia da educação virtual: aprender e ensinar com as tecnologias da informação e comunicação. Porto alegre, Artmed, 2010. 
COLL, C.; MARTÍ, E. La educacion escolar ante lãs nuevas tecnologias de La información. In: COLL, C., Palacios, J. eMARCHESI, A. (comps.) Desarrollo psicológico y educación. 2 ed. Psicología de La educaión escolar, Madrid, Alianza, p.623-651, 2001.

CORSINO, P. A brincadeira com as palavras, e as palavras como brincadeiras. In: CORSINO, P. Educação Infantil: cotidiano e políticas. Campinas, SP: Autores associados, 2012, p.47 a 64.

CZYZESWKI, L.; WERLE, K. O brincar no tempo e no espaço da Educação infantil. In: MELLI, D. T.; CANCIAN, V. A.; GALLINA, S. F. S. da. Formação para a docência na educação infantil: Pedagogias, Políticas e contextos. Porto Alegre: EDIPUCRS, 2017, p. 365-387.

FERREIRA, I. R.; FILHO, N. F. D. Criação de Narrativas Digitais Utilizando Elementos das Redes Sociais para Apoiar o Ensino de Eletrônica. Renote. V. $18 \mathrm{~N}^{\circ}$ 1, julho, 2020. Disponível em: https://seer.ufrgs.br/renote/article/view/106008/57852. Acesso em 18 de março de 2021.

FRIEDMAN, A. O direito de brincar: a brinquedoteca. São Paulo: Scritta/Abrinq, 2009. GIL, A. C. Como elaborar projetos de pesquisa. $6^{\circ}$ Ed. São Paulo: Atlas, 2017.

GOMES, S. S. dos. Formação de professores e letramento digital. In: Núcleo Práxis. Anais ciclo de palestras: construindo redes, educação e tecnologia. Relatório Procedência. Belo Horizonte: UFMG/CAPES, p.1-10, 2012.

GOMES, S. dos S.; Infância e tecnologias. In: COSCARELLI, C. V. (Org.) Tecnologias para aprender. 1 ed. - São Paulo: Parábola Editorial, 2016. Cap. 9, p. 146-158.

KISHIMOTO, T. M. O jogo, brinquedo, brincadeira e a educação. São Paulo, Cortez, 2011.

KOZINETS, R. V. Netnografia [recurso eletrônico]: realizando pesquisa etnográfica on-line / Robert V. Kozinets; tradução: Daniel Bueno; revisão técnica: Tatiana Melani Tosi, Raúl Ranauro Javales Júnior. - Dados eletrônicos. - Porto Alegre: Penso, 2014.

LALUEZA, J. L.; CRESPO, I.; CAMPS, S. As tecnologias da informação e da comunicação e os processos de desenvolvimento e socialização. In: COLL, C.; MONEREO, C. Psicologia da Educação Virtual: aprender e ensinar com as tecnologias da informação e da comunicação. Porto Alegre: Artmed, 2010.

MILLER, C. H. Digital Storytelling: a creator's guide to interactive entertainment. New York: Taylor e Francis, 2014.

MOYLES, J. R. Só brincar?O papel do brincar na Educação Infantil. Porto Alegre: Artmed, 2002.

NICOLOPOULOU, A. (2011) Children's Storytelling: Toward an Interpretive and Sociocultural Approach. Storyworlds, Vol. 3, p.25 - 48. Project Muse. Disponível em: < https://muse.jhu.edu/article/432690/pdf >. Acesso em: 20/01/2021.

ONG, C. C. (2011). Developing Core Communication Competencies Through Storytelling and Mobile Technologies. International Conference "ICT for language learning, $4^{\text {th }}$ Edition. Florence, Italy, 2011.

PSOMOS, P.; KORDAKI, M. Pedagogical Analysis of Education al Environments of the Last Five Years. Conference: 4th World Conference on Educational Sciences, Elsevier, Procedia - Social and Behavioral Sciences. Volume 46, 2012.

RINALDI, Carla. Diálogos com Réggio Emilia: escutar, investigar e aprender. Tradução: Vania Cury. São Paulo: Paz e Terra, 2012. 